\title{
Mobile Learning Adoption: The Case of Malaysian University Students
}

\author{
Mohamad Noorman Masrek, Mohd Sazili Shahibi \\ Faculty of Information Management \\ Universiti Teknologi MARA, Shah Alam \\ Malaysia
}

\begin{abstract}
Despite the availability of studies on mobile learning adoption, its theoretical foundations have not yet matured. In addition, studies on mobile learning adoption in the context of Malaysia is also still very limited. Against this concern, a study was undertaken with the aim of investigating factors that could influence mobile learning adoption. Building upon The Unified Theory of Acceptance and Use of Technology (UTAUT) and two other variables which are perceived playfulness and self management of learning, an empirical based framework was developed to identify predictors of mobile learning. Employing a survey research method involving 282 respondents from Universiti Teknologi MARA, the results showed that performance expectancy, effort expectancy, social factors, facilitating conditions, perceived playfulness and self management of learning are strong determinants of intention to adopt mobile learning. The present study provides both a theoretical and practical contributions to understanding the predictors of intention to adopt mobile learning and should be of interest to both researchers and practitioners.
\end{abstract}

\section{Introduction}

The revolution brought about by mobile technologies has resulted in the emergence of mobile learning (ML), which is the extension or prolongation of e-learning. ML is described as a learning process which takes the advantages of mobile devices, ubiquitous communications technology and intelligent user interfaces [15]. In universities, ML helps educational institutions to enhance the accessibility, interoperability and reusability of educational resources, and also to improve flexibility and interactivity of learning behaviors at convenient times and places [10]. For learners in general, ML facilitates the use of previously unproductive time, enables learning behaviors regardless of time and place; and brings about the great possibilities for personalized, customized and context-aware learning support services [8].

It is well acknowledged that the availability of technology itself does not guarantee that it will be accepted by the users or consumers, especially when it comes to using it for supporting the learning process. The mobile technology is not without exception. Despite its strong penetration into the lives of human being, there is no guarantee that it will also be used to support the learning process. As a matter of fact, the understanding of the adoption of mobile technologies in educational environments is still in its incipient stage. According to [11], while there were few studies on ML, its theoretical foundations were still immature. Questions about how to promote the acceptance of ML by users are still largely unresolved. Against this background, a study was conducted with the following objectives: (i) to identify factors that influence ML adoption among students in higher learning institution in Malaysia, and (ii) to ascertain whether the following factors influence intention to adopt ML: performance expectancy, effort expectancy, social factors, facilitating conditions, perceived playfulness and self management of learning.

The rest of this paper is structured as follows. Firstly, this study presents the literature review on ML, focusing on its concepts and related theories, model or framework used by researchers for studying ML adoption. Secondly, it describes the research method, giving the details on the measurement, population, sampling and data collection. Thirdly, it presents the results of the data analysis. Fourthly, it presents the discussion of the research findings. Finally, it draws the conclusion of the study.

\section{Literature review}

ML is defined as "handheld technologies, together with wireless and mobile phone networks, to facilitate, support, enhance and extend the reach of teaching and learning" [14]. Based on its characteristics, ML is said to be highly situated, personal, collaborative and long term [12].

The advantages of ML are (i) just-enough learning - highly applied, easily digestible learning for increasingly busy executives; (ii) just-in-time learning - convenient, flexible and relevant learning at the exact moment learning is required; (iii) justfor-me learning - learner-driven learning in a suitable format; (iv) cost-saving - ML can be cost effective and using a learner's own mobile device eliminates technological barriers to accessing learning [12].

Since the dawn of ML, researchers have studied factors that influence its adoption. Theories, models 
or framework such as Theory of Reasoned Action (TRA); Social Cognitive Theory (SCT); Technology Acceptance Model (TAM); Theory of Planned Behavior (TPB); Model of PC Utilization (MPCU); Innovation Diffusion Theory (IDT); and The Unified Theory of Acceptance and Use of Technology (UTAUT) [18] have been referred and adapted by researchers to investigate the ML adoption. Among the various theories and models, UTAUT was found to be the most adopted or referred in the context of ML. The literature suggests that UTAUT could explain up to $70 \%$ of technology acceptance behavior. UTAUT identified four key constructs which are performance expectancy, effort expectancy, social factors and facilitating conditions to have a direct influence on intention to adopt technology [18]. Previous studies on ML had empirically shown the contribution of these four constructs. Besides these four constructs, researchers have also explored the role of perceived playfulness and self management of learning. The reason for including perceived playfulness was because in the ML environment, the features of the applications were generally fun to explore and engage, making the users to be fully absorbed in its usage. On the other hand, self management of learning was also studied because ML environment promotes selflearning or student centered learning. In other words, the ML learning is best suited for users or students who are very independent or being supervised or facilitated minimally by the instructors. Drawing upon this premise, the present study will investigate the factors that influence the adoption of ML as shown in Figure 1.

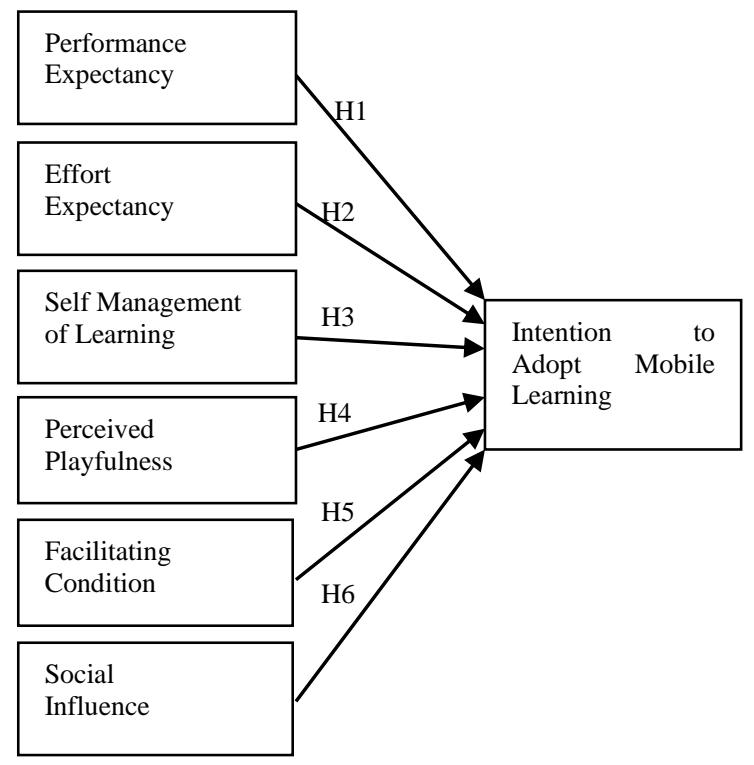

Figure 1. Theoretical Framework

\subsection{Intention to adopt ML}

Intention to adopt ML is defined as the person's subjective probability that he or she will adopt ML [18]. In the context ML adoption, various factors have been identified as predictors of intention to adopt. Among the factors identified were perceived mobility; perceived ease of use; perceived usefulness; alignment value; intrinsic value; utility value; self-management of learning; comfort with ML; perceived trust; performance expectancy; effort expectancy; social influence; perceived playfulness; relative advantage; facilitating condition; previous experience; resistance; importance of the course; integration of the technology into course assessment; lecturer modelling of the course; available tools; lecturer's feedback; mobile device and software; perceived innovativeness; perceived ICT anxiety; perceived self efficacy; compatibility; complexity; trialability; observability; image; voluntariness; cost and perceived credibility [9]. However, out of these long listing of variables, the eight most frequently examined factors were performance expectancy; effort expectancy; self management of learning; social influence; facilitating conditions; perceived playfulness, perceived cost and previous experience [9]. Except for perceived cost, all the aforesaid variables were found to have positive and significant relationship. As for perceived cost, a negative relationships was discovered. In other words, as the cost of acquiring the ML application gets higher, the interest to adopt ML will be lower.

\subsection{Performance expectancy}

Performance expectancy, which is described by [18], refers to "the degree to which an individual believes that using ML will help him or her to attain gains in job performance". Adapting performance expectancy to ML, suggests that users will find ML useful because it enables learners to accomplish learning activities more quickly, effectively and flexibly [19]. A study done in Taiwan discovered that performance expectancy was the strongest predictor of intention to adopt ML. A recent study in the context of Malaysia also showed consistent finding [6]. Other studies that had also discovered similar findings were from [4], [5] and [13]. Following the findings of the aforesaid studies, this study expects that performance expectancy is a significant predictor of the intention to adopt ML. Therefore, it is hypothesized that: H1: Performance expectancy significantly affects intention to adopt $M L$. 


\subsection{Effort expectancy}

Effort expectancy is "the degree of ease associated with the use of the system" [40]. In the context of ML, effort expectancy is about an individual's expectation of using ML without much effort. The easier the ML applications can be accessed by the user, the more is the intention to adopt it. Studies across different countries showed mixed results on the influence of effort expectancy on intention to adopt ML. While [6] did not find any support, others, such as [4], [5], [13], and [19] found a positive relationship between effort expectancy and intention to adopt ML. In the case of this study, the researcher argued that effort expectancy is an influential factor for adopting ML. Accordingly, this study posits that: H2: Effort expectancy significantly affects intention to adopt $M L$.

\subsection{Self management of learning}

Self management of learning is defined as the extent to which an individual feels he or she is selfdisciplined and can engage in autonomous learning [16]. The need for self-direction, or self-management of learning, runs clearly throughout the distance education and resource-based flexible learning literature [16]. Since ML can be considered as a kind of e-learning via mobile devices, it is expected that a person's level of self-management of learning will have a positive influence on his or her behavioral intention to adopt ML. In other words, ML adoption will be favorable to individual who work well independently. Previous study on ML found that self management of learning positively predicts intention to adopt ML [18]. To this effect, this study hypothesizes that: H3 - Self-management of learning significantly affects individual intention to adopt ML.

\subsection{Perceived Playfulness}

Perceived playfulness is considered as one of the critical factors that could potentially affect learning engagement with the utilization of new teaching innovations and technology. The literature suggests that perceived playfulness will provide intrinsic motivation when individuals become completely absorbed in a technology. An intrinsic motivator refers to the individual's performance or engagement in an activity due to his or her interest in the activity [28]. Previous studies have also shown that the use of IT is influenced by perceived playfulnessrelated constructs [14]. The reason is because individuals who experience pleasure or enjoyment from using an IT or information systems are more likely to intend to use it extensively than those who do not. Taken the above together, the researcher argued that this situation would also be applicable to the context of ML adoption. Hence, the study hypothesizes: H4 Perceived playfulness significantly affects individual intention to adopt $M L$.

\subsection{Facilitating conditions}

Facilitating condition is defined as "the degree to which an individual believes that an organizational and technical infrastructure exists to support the use of the system" [18]. Acceptance of any new technology is highly dependent upon the supporting conditions or environment [5]. In the context of ML, these facilitating conditions can appear in the form such as resources, knowledge, Internet speed, and support personnel [5]. Resources, in the form of learning content are considered the most crucial. In many ML applications, the contents are not fulfilling the needs of the students or users. Just as any form of computer-based information systems, the development of ML application should follow a rigorous process so as to ensure its final products are highly usable and meeting the needs of the users. A study reported by [5] showed that facilitating condition was a significant predictor of ML adoption. Given this background, this study postulates that: H5: Facilitating conditions significantly affect intention to adopt $M L$.

\subsection{Social Influence}

Social influence is defined as "the degree to which an individual perceives that others believe he or she should use the new system" [18]. It is also defined as the individual's internalization of the reference groups' subjective culture, and specific interpersonal agreements that the individual has made with others, in specific social situations. In theory, social influence can appear in three different forms: (i) compliance: when an individual accepts influence because he hopes to achieve a favorable reaction from another person or group (social approval/disapproval from others) (ii) identification: when an individual accepts influence because he wants to establish or maintain a satisfying selfdefining relationship with others; (iii) internalization: when an individual accepts influence because it is congruent with her value system [7]. In the mobile context, social influence appeared in two modes: one that exerts pressure on individuals to adopt, and another that helps to generate benefits via social networks that are tied in with economic and business networks [3]. Nonetheless, the studies by [4], [5] and [13] indicated that social influence was a significant predictor of ML adoption. Therefore, this study also expects a similar relationship and hypothesizes: H6: 
social influence significantly affects intention to adopt ML.

\section{Research Method}

This study employed a quantitative approach with a survey as the research method. The instrument used for data collection was a questionnaire. The questionnaire was developed by referring to the instruments used by previous studies. In particular, the instruments used by [5] and [19] were adapted as these two studies were also focusing on ML adoption. Perceptual measures in the form of statements were used for measuring each variable with a corresponding Likert scale anchored as 1 for "Strongly Disagree"; 2 for "Disagree"; 3 for "Neither Agree Nor Disagree"; 4 for "Agree" and 5 for "Strongly Agree". As shown in Table 1, a total of 24 items or statements was used for measuring the main variables or constructs. Before the main data collection, the questionnaire was pre-tested with several experts and prospective respondents. They were requested to give constructive comments and based on their feedback, the questionnaire was revised. Among the changes made, were in terms of sentence structure and the length of the questionnaire. Subsequently, it was pilot tested with 30 students. Their responses were analyzed using IBM SPSS software to identify the reliability score (i.e. Cronbach Alpha) for each variable in the framework. The results of the pilot test as illustrated in Table 1 showed that the Cronbach Alpha for all variables are well above 0.7 , indicating that the questionnaire was acceptably reliable.

Table 1. Sources of Measurement

\begin{tabular}{|l|c|c|l|}
\hline Variable & $\begin{array}{l}\text { No of } \\
\text { items }\end{array}$ & $\begin{array}{l}\text { Sources of } \\
\text { measurement }\end{array}$ & $\begin{array}{l}\text { Cronbach } \\
\text { Alpha of } \\
\text { pilot test }\end{array}$ \\
\hline $\begin{array}{l}\text { Intention to } \\
\text { adopt ML }\end{array}$ & 3 & {$[5],[19]$} & 0.76 \\
\hline $\begin{array}{l}\text { Performance } \\
\text { expectancy }\end{array}$ & 4 & {$[5],[19]$} & 0.723 \\
\hline $\begin{array}{l}\text { Effort } \\
\text { expectancy }\end{array}$ & 4 & {$[5],[19]$} & 0.811 \\
\hline $\begin{array}{l}\text { Self management } \\
\text { of learning }\end{array}$ & 3 & {$[5],[19]$} & 0.746 \\
\hline $\begin{array}{l}\text { Perceived } \\
\text { playfulness }\end{array}$ & 3 & [5], [19] & 0.722 \\
\hline $\begin{array}{l}\text { Facilitating } \\
\text { conditions }\end{array}$ & 3 & 0.707 \\
\hline Social influence & 3 & \\
\hline
\end{tabular}

The population of the study was students enrolled for the bachelors degree in the Faculty of Information Management, Universiti Teknologi MARA, Malaysia. Using the listing of registered students as the sampling frame, the simple random sampling technique was adopted to identify the targeted respondents. A total of 350 questionnaires was sent to the targeted students using printed (paper-based) and an online. The duration of data collection was one month and after the period was over, a total of 302 questionnaires was returned. However, 20 were found to be unusable for further analysis as they were incomplete. The remaining 282 were analyzed using IBM SPSS and AMOS version 20. The statistical analyses carried out were frequency analysis; descriptive analysis focusing on median, standard deviation, variance and testing normality of distribution; confirmatory factor analysis (CFA) for assessing the convergent validity and discriminant validity; and structural equation modeling (SEM) or structural model for testing the established hypotheses.

\section{Findings}

Table 2 showcases the demographic profile of the respondents. Out of 282 respondents, $73.8 \%$ were female while the remaining $26.2 \%$ were male. The higher number of female respondents was because $70 \%$ of the students in the faculty were female. In terms of semester of study, the majority indicated to be in semester three $(22.7 \%)$, followed by students from semester two (19.1\%) and semester five $(19.1 \%)$. The minority was from semester six $(12.4 \%)$. With regard to program registered, the majority of the respondents was doing BSc Information Management Systems (27.0\%) and followed by BSc Library Science (25.5\%).

Table 2. Demographic profiles

\begin{tabular}{|c|c|c|c|}
\hline Variable & & Frequency & Percent \\
\hline \multirow[t]{2}{*}{ Gender } & Male & 74 & 26.2 \\
\hline & Female & 208 & 73.8 \\
\hline \multirow[t]{6}{*}{ Semester } & 1 & 36 & 12.8 \\
\hline & 2 & 54 & 19.1 \\
\hline & 3 & 64 & 22.7 \\
\hline & 4 & 42 & 14.9 \\
\hline & 5 & 51 & 18.1 \\
\hline & 6 & 35 & 12.4 \\
\hline \multirow[t]{4}{*}{ Programs } & BSc Library Science & 72 & 25.5 \\
\hline & $\begin{array}{l}\text { BSc Information } \\
\text { Management } \\
\text { Systems }\end{array}$ & 76 & 27.0 \\
\hline & $\begin{array}{l}\text { BSc Records } \\
\text { Management }\end{array}$ & 67 & 23.8 \\
\hline & $\begin{array}{l}\text { BSc Resource Centre } \\
\text { Management }\end{array}$ & 67 & 23.8 \\
\hline
\end{tabular}

In order to identify whether the data is experiencing common method bias, Harman's single factor test was executed. All items from all constructs under study were entered for analysis and constrained to only a single factor. The results showed that the single factor explained only $26.29 \%$, less than the benchmark value of $50 \%$ of the total variance, implying that the collected data is free from 
the problem of common method variance. Normality testing on univariate and multivariate was also accessed upon the data. To test for univariate normality the skewness and kurtosis of each observed variable was assessed. The skewness and kurtosis requirements fulfilled the benchmark values which are 3 and 10 respectively. To assess multivariate normality, the Mardia's coefficient should be less than $\mathrm{p}(\mathrm{p}+2)$, where $\mathrm{p}$ is the number of observed variables. This study has 24 observed variables, so $24 \mathrm{X}(24+2)=624$. The Amos output for Mardia's coefficient is 68.56 , which is less than 624 , hence multivariate normality can be assumed.

To assess the convergent validity, this study used factor loadings, composite reliability (CR) and the average variance extracted (AVE). The recommended value of factor loadings should be above the value of 0.6 and as shown in Table 3 , all the factor loadings met this requirement. In terms of composite reliability, all the scores are well above the cutoff value of 0.7 . The literature suggests that the acceptable level of AVE should be more than 0.5 which is also fulfilled in this study as illustrated in Table 3. Accordingly, the study also assessed discriminant validity and the results are presented in Table 3. It is suggested that AVE can also be used to assess discriminant validity by comparing its square root against the correlation values between the variables and all other variables. As displayed in Table 4, the square root of the AVE values is well above the correlation values, hence suggesting discriminant validity requirement is also fulfilled. The AMOS output of the measurement model is shown in Figure 2.

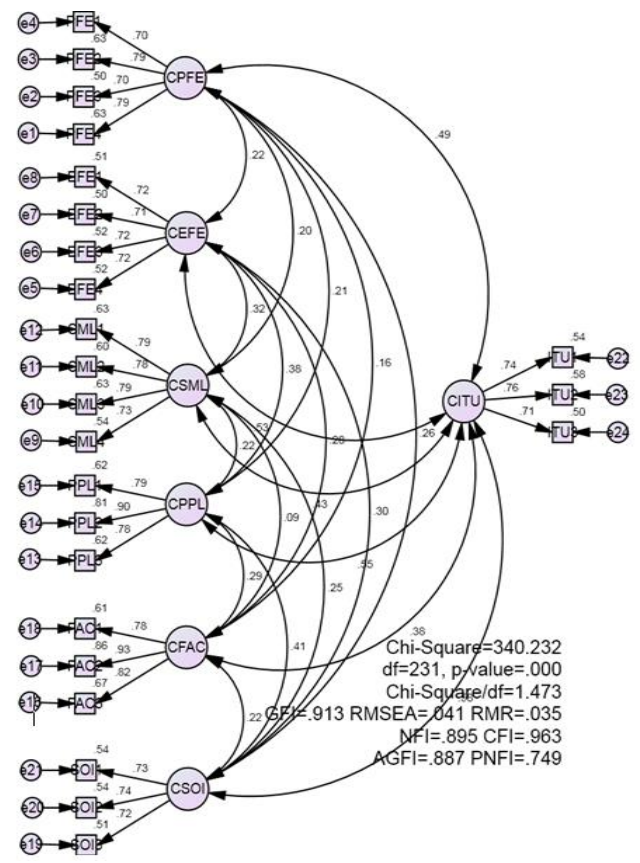

Figure 2. Measurement Model
Table 3. Convergent Validity

\begin{tabular}{|c|c|c|c|c|}
\hline $\begin{array}{l}\text { Model } \\
\text { constructs }\end{array}$ & Item & Loading & $\begin{array}{l}\text { Composite } \\
\text { Reliability } \\
\text { (CR) }\end{array}$ & $\begin{array}{l}\text { Average } \\
\text { Variance } \\
\text { Extracted } \\
\text { (AVE) }\end{array}$ \\
\hline \multirow{3}{*}{$\begin{array}{l}\text { Intention to } \\
\text { adopt } \\
\text { (CITU) }\end{array}$} & ITU1 & 0.737 & \multirow[t]{3}{*}{0.780} & \multirow[t]{3}{*}{0.542} \\
\hline & ITU2 & 0.761 & & \\
\hline & ITU3 & 0.710 & & \\
\hline \multirow{4}{*}{$\begin{array}{l}\text { Self } \\
\text { Management } \\
\text { Learning } \\
\text { (CSML) }\end{array}$} & SML1 & 0.734 & \multirow[t]{4}{*}{0.857} & \multirow[t]{4}{*}{0.600} \\
\hline & SML2 & 0.794 & & \\
\hline & SML3 & 0.775 & & \\
\hline & SML4 & 0.793 & & \\
\hline \multirow{3}{*}{$\begin{array}{l}\text { Social } \\
\text { Influence } \\
(\mathrm{CSOI})\end{array}$} & SOI1 & 0.734 & \multirow[t]{3}{*}{0.772} & \multirow[t]{3}{*}{0.531} \\
\hline & SOI2 & 0.736 & & \\
\hline & SOI3 & 0.715 & & \\
\hline \multirow{3}{*}{$\begin{array}{l}\text { Facilitating } \\
\text { Conditions } \\
(\mathrm{CFAC})\end{array}$} & FAC1 & 0.780 & \multirow[t]{3}{*}{0.881} & \multirow[t]{3}{*}{0.713} \\
\hline & FAC2 & 0.928 & & \\
\hline & FAC3 & 0.819 & & \\
\hline \multirow{4}{*}{$\begin{array}{l}\text { Performance } \\
\text { Expectancy } \\
(\mathrm{CPFE})\end{array}$} & PEE1 & 0.704 & \multirow[t]{4}{*}{0.837} & \multirow[t]{4}{*}{0.563} \\
\hline & PEE2 & 0.792 & & \\
\hline & PEE3 & 0.705 & & \\
\hline & PEE4 & 0.794 & & \\
\hline \multirow{3}{*}{$\begin{array}{l}\text { Perceived } \\
\text { Playfulness } \\
(\mathrm{CPPL})\end{array}$} & PPL1 & 0.789 & \multirow[t]{3}{*}{0.865} & \multirow[t]{3}{*}{0.682} \\
\hline & PPL2 & 0.898 & & \\
\hline & PPL3 & 0.785 & & \\
\hline \multirow{4}{*}{$\begin{array}{l}\text { Effort } \\
\text { Expectancy } \\
\text { (CEFE) }\end{array}$} & EFE1 & 0.717 & \multirow[t]{4}{*}{0.808} & \multirow[t]{4}{*}{0.512} \\
\hline & EFE2 & 0.707 & & \\
\hline & EFE3 & 0.718 & & \\
\hline & EFE4 & 0.721 & & \\
\hline
\end{tabular}

Table 4. Discriminant Validity

\begin{tabular}{|l|l|l|l|l|l|l|l|}
\hline & {$[1]$} & {$[2]$} & {$[3]$} & {$[4]$} & {$[5]$} & {$[6]$} & {$[7]$} \\
\hline $\begin{array}{l}\text { CITU } \\
{[1]}\end{array}$ & 0.736 & & & & & & \\
\hline $\begin{array}{l}\text { CSML } \\
{[2]}\end{array}$ & 0.429 & 0.774 & & & & & \\
\hline $\begin{array}{l}\text { CSOI } \\
{[3]}\end{array}$ & 0.581 & 0.255 & 0.728 & & & & \\
\hline $\begin{array}{l}\text { CFAC } \\
{[4]}\end{array}$ & 0.381 & 0.089 & 0.381 & 0.844 & & & \\
\hline $\begin{array}{l}\text { CPFE } \\
{[5]}\end{array}$ & 0.486 & 0.202 & 0.486 & 0.202 & 0.750 & & \\
\hline $\begin{array}{l}\text { CPPL } \\
{[6]}\end{array}$ & 0.550 & 0.225 & 0.550 & 0.225 & 0.550 & 0.825 & \\
\hline $\begin{array}{l}\text { CEFE } \\
{[7]}\end{array}$ & 0.527 & 0.319 & 0.527 & 0.319 & 0.527 & 0.319 & 0.715 \\
\hline
\end{tabular}

In SEM, the fit criteria are assessed in terms of absolute fit measures, incremental fit measures and also parsimony fit measures. As illustrated in Table 5 , the $\chi^{2}$ statistic suggests that the data do not fit the model well $\left(\chi^{2}=340.232\right.$, df $=231$, p-value $\left.<0.05\right)$. However, because $\chi^{2}$ is easily affected by sample size, the $\chi^{2}$ statistic is not always an appropriate measure of a model's goodness-of-fit. Therefore other fit indices as shown in Table 5 are used to examine the model's goodness-of-fit. Apparently, all fit indices surpassed the fit criteria suggesting that the SEM model fits the data very well.

Figure 3 displays the AMOS output of the structural model while Table 6 showcases the path coefficients between the independent variables and a dependent variable. The Squared Multiple Correlation $\left(\mathrm{R}^{2}\right)$ value for the relationship between the six independent variables and intention to adopt 
was 0.650. The results also indicated that all hypotheses were fully supported as the p-values for all paths are well below 0.05 . The coefficient values $(\beta)$ range between 0.100 and 0.265 . Figure 2 depicts the path diagram between the independent and dependent variables.

Table 5. Fit Indices of the Model

\begin{tabular}{|l|c|c|}
\hline Fit Index & \multicolumn{1}{|c|}{$\begin{array}{c}\text { Fit } \\
\text { Criteria }\end{array}$} & $\begin{array}{c}\text { Measurement } \\
\text { Model }\end{array}$ \\
\hline Chi Square $\left(\chi^{2)}\right.$ & & 340.232 \\
\hline Degrees of freedom & $\geq 0.5$ & 231 \\
\hline P-value (probability) & 3 & 0.000 \\
\hline Absolute fit measures & $\geq 0.9$ & 0.913 \\
\hline CMIN $\left(\chi^{2}\right) /$ DF & $\leq 0.05$ & 0.041 \\
\hline GFI (Goodness of Fit Index) & $\leq 0.05$ & 0.035 \\
\hline $\begin{array}{l}\text { RMSEA (Root Mean Square } \\
\text { Error of Approximation) }\end{array}$ & $\geq 0.9$ & 0.900 \\
\hline $\begin{array}{l}\text { RMR (Root Mean Square } \\
\text { Residual) }\end{array}$ & $\geq 0.9$ & 0.963 \\
\hline Incremental fit measures & $\geq 0.8$ & 0.887 \\
\hline NFI (Normed Fit Index) & $\geq 0.5$ & 0.749 \\
\hline CFI (Comparative Fit Index) & \\
\hline Parsimony Fit Measures & \begin{tabular}{l}
$\mid$ \\
\hline $\begin{array}{l}\text { AGFI (Adjusted Goodness of Fit } \\
\text { Index) }\end{array}$
\end{tabular} \\
\hline $\begin{array}{l}\text { PNFI (Parsimonious Normed Fit } \\
\text { Index) }\end{array}$ & $\geq$ \\
\hline
\end{tabular}

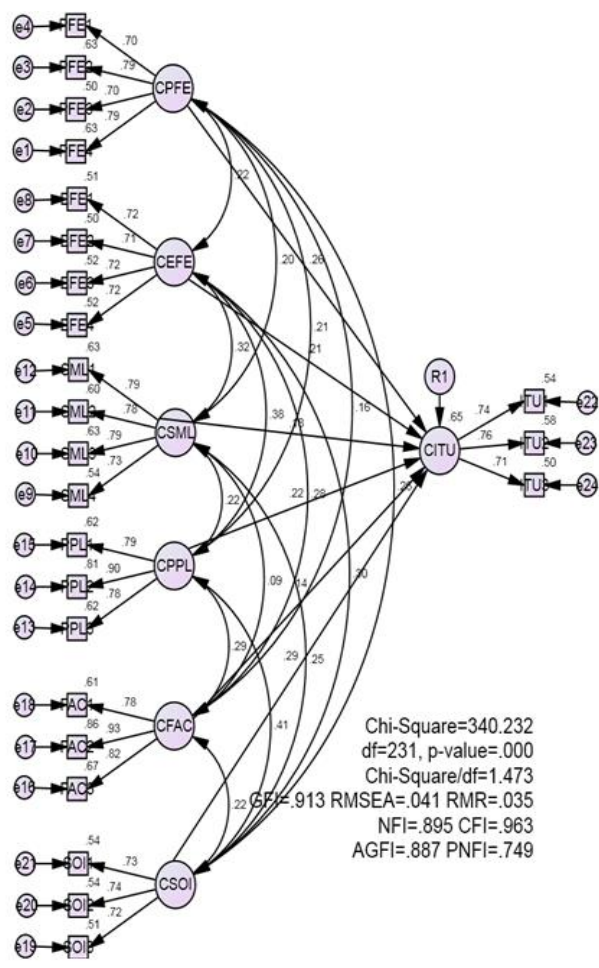

Figure 3. Structural Model
Table 6. Hypotheses Testing

\begin{tabular}{|l|c|c|c|}
\hline Hypothesis & $\beta$ & $\begin{array}{c}\mathrm{t}- \\
\text { value }\end{array}$ & $\mathrm{p}$-values \\
\hline $\begin{array}{l}\text { H1: Performance } \\
\text { expectancy } \rightarrow \text { intention } \\
\text { to adopt }\end{array}$ & 0.197 & 4.297 & $<0.01$ \\
\hline $\begin{array}{l}\text { H2: Effort expectancy } \rightarrow \\
\text { intention to adopt }\end{array}$ & 0.164 & 2.903 & $<0.01$ \\
\hline $\begin{array}{l}\text { H3: Self management of } \\
\text { learning } \rightarrow \text { intention to } \\
\text { adopt }\end{array}$ & 0.146 & 2.909 & $<0.01$ \\
\hline $\begin{array}{l}\text { H4: Perceived } \\
\text { playfulness } \rightarrow \text { intention } \\
\text { to adopt }\end{array}$ & 0.184 & 2.448 & $<0.01$ \\
\hline $\begin{array}{l}\text { H5: Facilitating condition } \\
\rightarrow \text { intention to adopt }\end{array}$ & 0.100 & 2.448 & $<0.01$ \\
\hline $\begin{array}{l}\text { H6: Social influence } \rightarrow \\
\text { intention to adopt }\end{array}$ & 0.265 & 3.961 & $<0.01$ \\
\hline
\end{tabular}

\section{Discussion}

The present study provides both a theoretical and practical contributions to understanding the predictors of intention to adopt ML. The findings of this study should be of interest to both researchers and practitioners. The results generated from the path analysis indicate that the combination of the six independent variables accounts for $65 \%$ of the variance in intention to adopt ML. This result suggests that $65 \%$ of the variance in intention to adopt ML can be explained by performance expectancy, effort expectancy, social influence, facilitating conditions, perceived playfulness and self management of learning.

This study has significantly recognized the influence of performance expectancy on intention to adopt ML $(\beta=0.197, p<0.01)$. The result is consistent with [4], [5], [6], [13], and [19]. The results suggest that, the more students perceive that ML is useful for learning and improves their productivity; the more likely they are to engage in ML.Theoretically, this result further strengthens UTAUT in predicting ML adoption. The scale used for measuring performance expectancy focused on increased performance, productivity, and effectiveness. From the practical viewpoint, the findings send a strong message on the importance for increasing student performance expectancy. Educators and administrators could perhaps play a role by promoting the benefits and usefulness of ML to their students and encourage them to use their mobile devices for information searching, engaging in online group discussions or completing other learning activities.

Just as performance expectancy, effort expectancy which is derived from UTAUT was also found to be a significant predictor of ML adoption ( $\beta$ $=0.164, \mathrm{p}<0.01)$. The result is in tandem with that of [4], [5], [6], [13], and [19] which means that the more students perceive that ML is easy to use for 
learning; the more likely they are to engage in ML. Effort expectancy construct is similar with perceived ease of use, which is defined as the degree to which a person believes that the use of a particular system would be free of effort. The items used for measuring effort expectancy focused on the degree of difficulty on using ML. Today, among students of Malaysian universities, the use of mobile devices, especially smart phones is very common. Perhaps, due to the fact that using a mobile device appears to be routine for most of these students; therefore they may perceive using it will not require much of their efforts, as it is just similar to using it for other tasks. Nevertheless, this finding has provided additional support for UTAUT in predicting ML. The implication to practitioner is that, when developing ML applications, serious attention should be given to user-friendliness aspects.

The third hypothesis of this study is between self management of learning and intention to adopt ML. Compared to the constructs of UTAUT, this variable is not very extensively studied in the context of ML. The result of this study has shown that this construct is indeed applicable in determining intention to adopt ML $(\beta=0.146, p<0.01)$. This result is in line with the finding of [19]. This finding implies that individual with a highly autonomous learning ability will be more likely to use ML than will an individual with a lower autonomous learning ability. Given this finding, ML developers should respond by developing ML applications that are equipped with features that are suitable for those who are highly independent in their learning processes. On the other hand, educators and administrator can also play a role by grooming their students to be more independent and adapt themselves to be more self learning.

The results of this study also recognized, perceived playfulness as a significant predictor of intention to adopt ML $(\beta=0.184, p<0.01)$. This finding further supports previous studies done by [4] and [19]. The result implies that the more students enjoy the ML, the more they will be motivated to engage in ML activities. [41] stated that, given that the use of ML is fully voluntary and that the target user group consists of a large number of people with very diversified backgrounds, making the ML system playful and enjoyable to interact with, is crucial for attracting more users to the ML system. Therefore, ML developers should react to this finding by enriching their ML applications with enjoyable and entertaining features.

Consistent with [4] and [5], this study has also found that facilitating condition as an essential predictor of intention to adopt ML $(\beta=0.184$, $p<$ 0.01 ). This finding suggests that student will not be attracted to adopt ML in the absence of facilitating conditions. In the context of Malaysia, all university students are entitled to a special voucher for purchasing smart phones. On top of that, the free wireless networks, available in the universities as well as in other public places such as bistros, restaurants and public libraries provide convenient internet access to the students. Nonetheless, this finding should alert the authorities concerned with the importance of the continuous update and upgrade of the infrastructure or facilities required for the implementation of ML.

The last construct being studied is social influence, which is also drawn from UTAUT. The results confirmed that social influence is a significant predictor of intention to adopt ML $(\beta=0.265$, $p<$ 0.01 ). In fact, in this study, social influence is found to be the strongest predictors compared to other constructs. This result is also consistent with that of [4], [5], [6], [13], and [19]. Based on the result, it can be concluded that the more students perceive faculty, peers, and other individuals important to them believe they should use ML, the more likely they are to engage in ML. Given this finding, it is crucial that people who have a strong connection with the students such as the lecturers, colleagues or even family members, should persistently encourage the student to engage in ML.

\section{Conclusion}

The purpose of this article has been to explore factors that influence the intention of users to adopt ML. To achieve this purpose, an empirical based framework drawn from UTAUT and previous empirical studies has been developed. The results of the analyses of the collected data significantly verified the established hypotheses. The results suggest that performance expectancy, effort expectancy, social factors, facilitating conditions, perceived playfulness and self management of learning are strong determinants of intention to adopt ML.

Just like in any other research, there are several limitations associated with the conduct of this study. Firstly, is the choice of students that was confined to one university only. Future study, should consider extending the scope of population by taking students of other universities. Secondly, the study did include other important variables as discussed in the literature review section. In the future, researchers should also consider including variables such as perceived cost and past experience. In addition, as indicated in the UTAUT model, it would also be equally interesting to examine the moderating effect such as age and gender in future study.

\section{Acknowledgements}

The researchers would like to extend his thanks to the students from the Faculty of Information 
Management, Universiti Teknologi MARA who had willingly participated in this study. Special thanks are also owed to the Faculty of Information Management and Universiti Teknologi MARA, Shah Alam, Malaysia for providing all the necessary resources required for the completion of the study.

\section{References}

[1] Agarwal R. and Karahanna, E. (2000) 'Time flies when you're having fun: Cognitive absorption and beliefs bout information technology usage', MIS Quarterly, 24(4) pp. 665-694.

[2] Chung, J and Tan, B. (2004) 'Antecedents of Perceived Playfulness: An Exploratory Study on User Satisfaction of General Information Searching Websites', Information \& Management 41(7), pp. 869-881.

[3] De Silva, H., Ratnadiwakara, D. and Zainudeen, A. (2011) 'Social Influence in Mobile Phone Adoption: Evidence from the Bottom of the Pyramid in Emerging Asia', Mobile Telephony Special Issue 7(3), pp. 1-18.

[4] Hadi F. Z. and Kishik, A. A. (2014) 'Acceptance of Mobile Learning Among University Students in Malaysia', Journal of Computing \& Organizational Dynamics 1(1).

[5] Iqbal, S. and Qureshi, I. A. (2012) 'M-learning Adoption: A Perspective From a Developing Country', The International Review of Research in Open and Distance Learning 13(3), pp. 147-164.

[6] Jambulingam, M. (2013) 'Behavioural Intention to Adopt Mobile Technology among Tertiary Students', World Applied Sciences Journal, 22(9), pp. 1262-1271.

[7] Kelman, H.C. (1958) 'Compliance, identification, and internalization: three processes of attitude change', The Journal of Conflict Resolution 2(1), pp. 51-60.

[8] Liu, Y. (2011) Solving the Puzzle of Mobile Learning Adoption. Unpublished Doctoral Thesis, Department of Information Technologies, Faculty of Technology, Åbo Akademi University.

[9] Momani, F. M. S. M. and Abualkishik, A. M. (2014) 'Factors Influencing Students' Intention to Adopt Mobile Blackboard', International Journal of Science and Research 3(5), pp. 29-32.

[10] Murphy, A. (2006) 'Mobile Learning in a Global Context: A Training Analysis'. in Proceeding of the International Conference on Networking, International Conference on Systems and International Conference on Mobile Communications and Learning Technologies.

[11] Muyinda, P. B. (2007) 'MLearning: Pedagogical, Technical and Organizational Hypes and Realities', Campus-Wide Information Systems 24(2), 97-104.

[12] Naismith, L., Lonsdale, P., Vavoula, G. and Sharples, M. (2004) Mobile Technologies and Learning. In Futurelab Literature Review Series, Report No 11.

[13] Nassuora, A. B. (2013) 'Students Acceptance of Mobile Learning for Higher Education in Saudi Arabia', International Journal of Learning Management Systems 1(1), pp. 1-9.

[14] Schofield, C. P., West, T. and Taylor E. (2011) Going Mobile In Executive Education How Mobile Technologies Are Changing The Executive Learning Landscape, Berkhamsted Hertfordshire Ashridge.

[15] Sharma S. K. and Kitchens, F. L. (2004) 'Web Services Architecture for M-learning', Electronic Journal for E-Learning, 2(1), pp. 203-216.

[16] Smith, P. J., Murphy, K. L. et. al. (2003) 'Towards Identifying Factors Underlying Readiness for Online Learning: An Exploratory Study', Distance Education, 24 (1) pp. 57-67.
[17] Taylor S. and Todd, P.A. (1995) 'Assessing IT Usage: the role of prior experience', MIS Quarterly 19(2), pp. 561-570.

[18] Venkatesh, V., Morris, M. G., Davis, G. B. and Davis, F. D. (2003) 'User Acceptance of Information Technology: Toward a unified view', MIS Quarterly 27(3), pp. 425-478.

[19] Wang, Y. S., Wu, M. C. and Wang, H. Y. (2009) 'Investigating The Determinants and Age and Gender Differences in the Acceptance of Mobile Learning', British Journal of Educational Technology 40(1), pp. 92-118, 2009. 